\title{
Calcified left atrial myxoma with floppy mitral valve
}

\author{
G. P. SHARRATT, M. L. GROVER, AND J. L. MONRO \\ From Wessex Cardiothoracic Centre, Southampton
}

SUMMARY A heavily calcified left atrial myxoma in a man aged 53 was diagnosed from the plain chest $x$ ray film and confirmed by echocardiography. There was also moderate mitral regurgitation caused by a floppy mitral valve. Before a systemic embolus is considered to have arisen from a floppy mitral valve, echocardiography must be performed.

Myxomata of the left atrium usually present with the features of mitral valve obstruction, systemic emboli, or constitutional symptoms (Goodwin, 1963). Mitral regurgitation is a rare presenting feature (Penny et al., 1967). We report the case of a patient who presented with cerebral embolism and the signs of mitral regurgitation, in whom a calcified left atrial myxoma was found by $x$-ray film and echocardiography.

\section{Case report}

A 53-year-old man was referred for consideration of mitral valve replacement for mitral regurgitation." He was thought to have had rheumatic fever as a child and mitral murmurs had been present for at least 20 years. He was seen by a physician in 1971 for dyspepsia and was thought to have mitral regurgitation. He was then in sinus rhythm. Three months before admission to this unit he had been admitted elsewhere with a right hemiparesis which was thought to be caused by a cerebral embolus associated with the onset of atrial fibrillation. He had made a complete neurological recovery but complained of dyspnoea on moderate effort.

On examination there was atrial fibrillation, all the peripheral pulses were present and normal, blood pressure $140 / 80 \mathrm{mmHg}$. The jugular venous pressure and pulse were normal. There was a moderately increased, dynamic, left ventricular impulse palpable at the anterior axillary line. A grade 2/4 apical pansystolic murmur with late crescendo radiated to the axilla. There was a soft short mitral diastolic murmur. The electrocardiogram confirmed atrial fibrillation and showed unifocal ventricular extrasystoles. The chest $x$-ray film (Fig. 1) showed a calcified mass within the left atrium. A diagnosis of a moderate mitral regurgitation with a calcified left atrial myxoma or thrombus was made. Echocardiography (Fig. 2a and 2b)

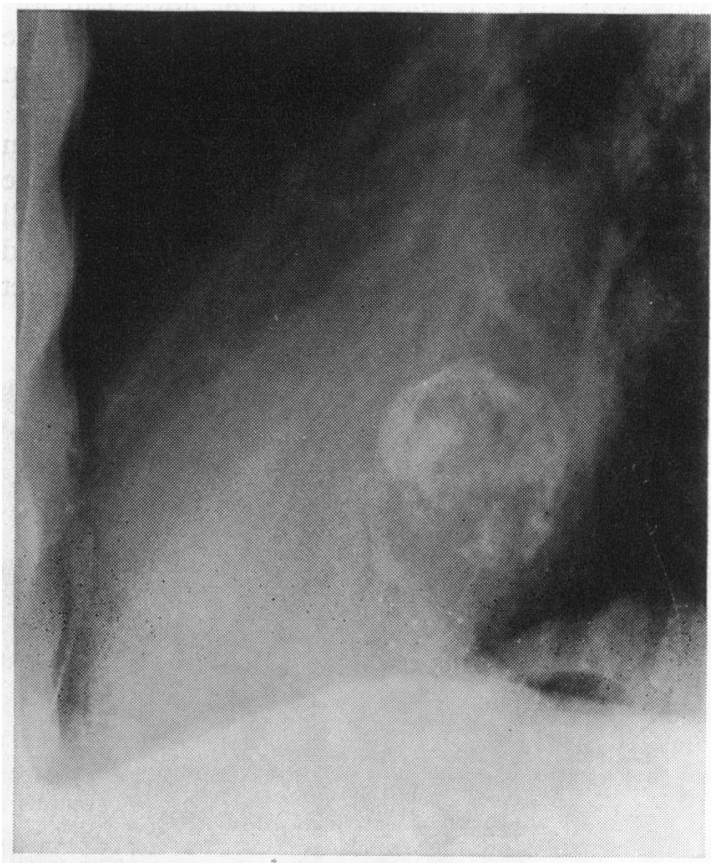

Fig. 1 Plain lateral chest $\mathrm{x}$-ray film showing a calcified mass in the region of the left atrium.

suggested mitral valve prolapse and confirmed a dense mass in the left atrium which did not pass through the mitral valve in diastole. The haemoglobin was $15 \cdot 1 \mathrm{~g} / \mathrm{dl}$ and the white blood cell count, platelets, and plasma proteins were normal. The ESR was $33 \mathrm{~mm}$ in one hour.

Operation was performed without further investigation. The left atrium was found to contain a hard smooth, yellowish tumour measuring $5 \mathrm{~cm}$ by 2.5 $\mathrm{cm}$. The mass was attached by a short pedicle to the posterior left atrial wall just below and medial to the right inferior pulmonary vein and $2 \mathrm{~cm}$ from the mitral valve. It was excised, together with its 


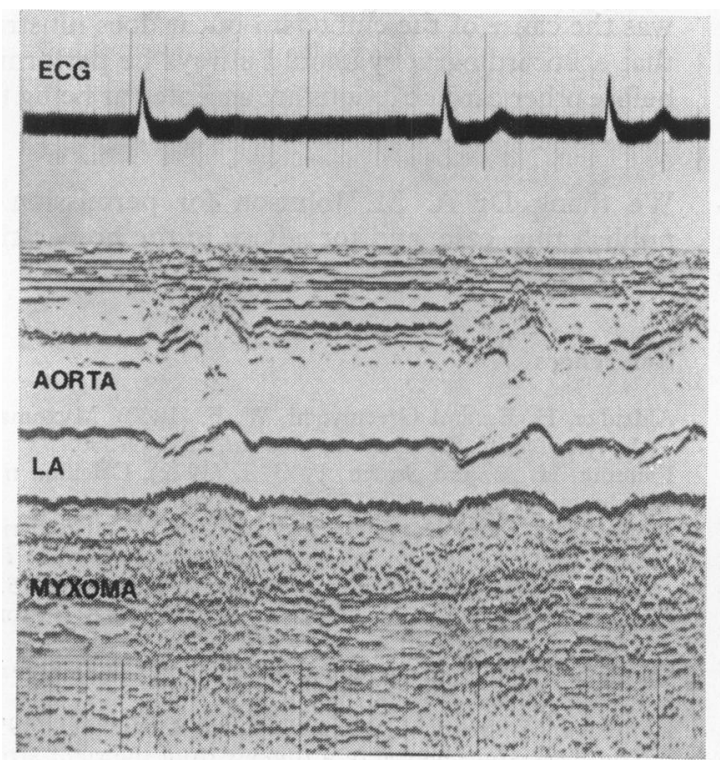

Fig. 2(a)

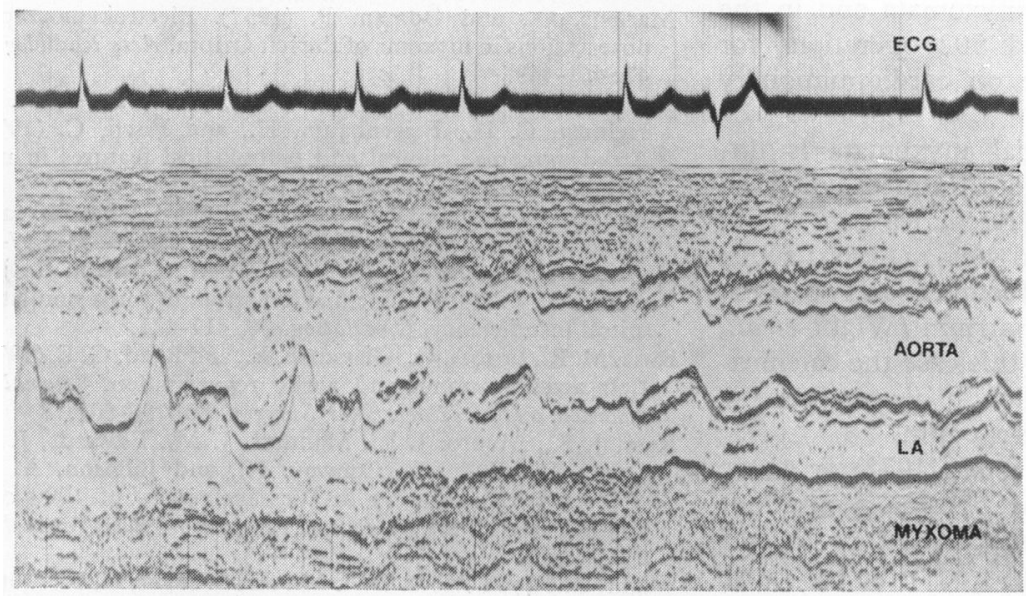

Fig. 2(b)

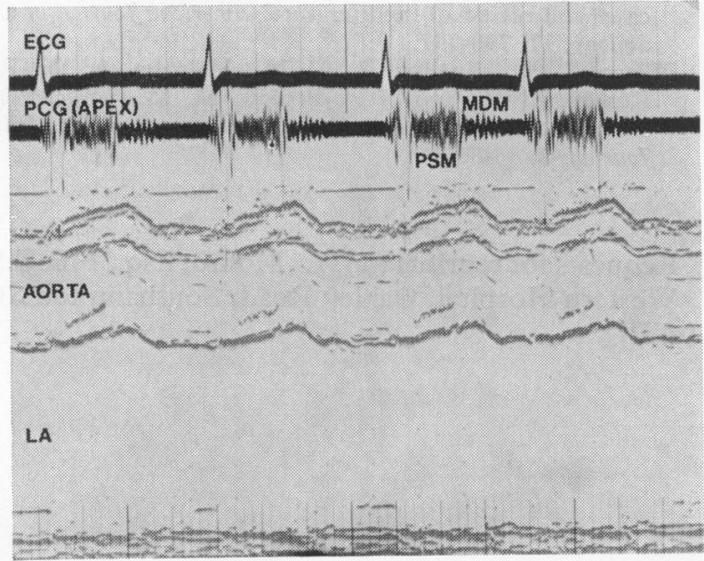

Fig. 2(c)

Fig. 2 (a) Echocardiogram of the aorta and left atrium ( $L A)$ showing a mass of echoes in the left atrium caused by the myxoma. (b) Echocardiographic sweep from the mitral valve to the aorta and left atrium. The echo mass does not prolapse through the mitral valve. There appears to be pansystolic prolapse of the mitral valve. (c) Echocardiogram of the aorta and left atrium. The left atrium is now echo free but enlarged to $5 \mathrm{~cm}$. The apical phonocardiogram (PCG) shows a pansystolic murmur (PSM) with late systolic crescendo, and a mitral diastolic murmur (MDM). 
pedicle and the related disc of atrial wall. The mitral valve appeared to be of the floppy type, and on testing was thought to be only mildly regurgitant and was therefore not replaced.

Postoperative recovery was uneventful. He continued to have signs of moderate mitral regurgitation, and echocardiography (Fig. 2c) confirmed that the left atrium was now echo free but enlarged. He was asymptomatic.

Histology of the mass showed the typical features of an atrial myxoma, with calcification.

\section{Discussion}

Atrial myxomata, once considered to be extremely rare, are now being diagnosed with increasing frequency. Greenwood (1968) reported an incidence of 1 in 200 to 400 operations for mitral valve obstruction. The Wessex Cardiothoracic Centre serves a population of 2.7 million people that may be considered to show a representative distribution of cardiac diseases (Ross et al., 1976). In the past 5 years we have seen 7 atrial myxomata and in the same period have performed 502 operations for isolated mitral valve disease on cardiopulmonary bypass.

Heavy calcification of atrial myxomata is uncommon and appears to be more frequent when the tumour is in the right atrium (Krcilkova et al., 1958; Wight et al., 1963; Oliver and Missen, 1966; Fluck and Lopez-Bescos, 1968; Fleming and Stoven, 1972) rather than in the left atrium (Wight et al., 1963; Penny et al., 1967). In this case the calcification was heavy enough to allow a diagnosis to be made from the lateral chest $x$-ray film.

The mitral valve (Nasser et al., 1972) or aortic valve (Rose et al., 1974) may become regurgitant because of damage from tumour motion. In this case mitral valve prolapse appeared to be the cause of the mitral regurgitation and at surgery the appearances were those of a floppy mitral valve. Rheumatic mitral disease has been reported in association with left atrial myxoma (Marions and Ödman, 1957; Aldridge and Greenwood, 1960), but we are not aware of any previous report of left atrial myxoma coexisting with floppy mitral valve.

Systemic emboli have been reported as a complication of the floppy mitral valve (Wilson et al., 1977). In the case here reported it is not possible to know whether this, the myxoma, or the atrial fibrillation was the cause of the embolism but it does illustrate that echocardiography should always be performed before other cardiac lesions are accepted as being the cause of systemic embolism.

We thank Dr A. M. Johnson for permission to publish this case, and for advice in the preparation of the manuscript.

\section{References}

Aldridge, H. E., and Greenwood, W. F. (1960). Myxoma of the left atrium. British Heart fournal, 22, 189-200.

Fleming, H. A., and Stovin, P. G. I. (1972). Calcified right atrial mass. Thorax, 27, 373-381.

Fluck, D. C., and Lopez-Bescos, L. (1968). Calcified right atrial myxoma producing tricuspid incompetence. Proceedings of the Royal Society of Medicine, 61, 1115-1118.

Goodwin, J. F. (1963). Diagnosis of left atrial myxoma. Lancet, 1, 464-468.

Greenwood, W. F. (1968). Profile of atrial myxoma. American fournal of Cardiology, 21, 367-375.

Krcilkova, M., Musil, J., Navratil, J., and Olejnik, O. (1958). The successful removal of a tumour from the right atrium under hypothermia. Thorax, 13, 173-176.

Marions, O., and Ödman, P. (1957). Electrokymographic observations in myxoma of the left atrium. Acta Radiologica, 47, 461-469.

Nasser, W. K., Davis, R. H., Dillon, J. C., Tavel, M. E., Helmen, C. H., Feigenbaum, H., and Fisch, C. (1972). Atrial myxoma: clinical and pathological features in nine cases. American Heart Fournal, 83, 694-704.

Oliver, G. C., and Missen, G. A. K. (1966). A heavily calcified right atrial myxoma. Guy's Hospital Reports, 115, 37-63.

Penny, J. L., Gregory, J. J., Ayrea, S. M., Gianelli, S., jun, and Rossi, P. (1967). Calcified left atrial myxoma simulating mitral insufficiency. Circulation, 36, 417-421.

Rose, M. R., Fox, A. C., Glassman, E., and Reed, G. E. (1974). Left atrial myxoma and aortic regurgitation. Fournal of Thoracic and Cardiovascular Surgery, 68, 798-801.

Ross, J. K., Monro, J. L., Manners, J. M., Edwards, J. C., Lewis, B., Hyde, I., Conway, N., and Johnson, A. M. (1976). Cardiac surgery in Wessex: review of 1000 consecutive open heart procedures. British Medical fournal, 2, 1485-1489.

Wight, R. P., jun, McGall, M. M., and Wenger, N. K. (1963). Primary atrial tumor, evaluation of clinical findings in ten cases and review of the literature. American fournal of Cardiology, 11, 790-797.

Wilson, L. A., Keeling, P. W. N., Malcolm, A. D., Ross Russell, R. W., and Webb-Peplow, M. M. (1977). Visual complications of mitral leaflet prolapse. British Medical fournal, 2, 86-88.

Requests for reprints to J. L. Monro, Esq., F.R.C.S., Western Hospital, Oakley Road, Southampton SO9 4WQ. 